\title{
Balancing pulmonary blood flow: Theory, in vitro measurements, and clinical correlation of systemic-to-pulmonary shunt banding
}

Cori R. Atlin, MD, Christoph Haller, MD, Osami Honjo, MD, PhD, Anusha Jegatheeswaran, MD, PhD, and

Glen S. Van Arsdell, MD

\begin{abstract}
Background: Size mismatch between body and a systemic-to-pulmonary shunt can result in excessive pulmonary blood flow, compromising systemic oxygen delivery. Previously reported techniques to mechanically restrict shunt flow lack precision and reproducibility. We developed a formula for shunt banding and assessed its efficacy and reproducibility by in vitro and clinical measurements.
\end{abstract}

Methods: Formulas to determine diameter reduction, length of banding, and effect on the ratio of pulmonary blood flow $\left(Q_{p}\right)$ to systemic blood flow $\left(Q_{s}\right)$ were established. In vitro measurements of different shunt grafts were performed. Results were compared with calculations and clinical data. Clinical outcome was retrospectively assessed in all patients $(n=8)$ who underwent a shunt banding procedure at our institution between 2008 and 2012.

Results: Our formulas can adequately predict the length of the band based on the desired diameter and shunt type or on the $\mathrm{Q}_{\mathrm{p}}: \mathrm{Q}_{\mathrm{s}}$ mismatch. In vitro measurements correlated with the manufacturer's specifications in small shunts $(\leq 5 \mathrm{~mm}$ diameter; $0.45 \mathrm{~mm}$ mean wall thickness). The calculated diameters of these shunts were closely correlated with in vitro measurements $(r=0.953 ; P=.001)$. Arterial saturation, $\mathrm{pH}$, and calculated $\mathrm{Q}_{\mathrm{p}}: \mathrm{Q}_{\mathrm{s}}$ decreased significantly with banding ( $P=.026, .002$, and .004, respectively). Clinical effects varied among patients, with hemodynamically stable patients achieving the most benefit. Adjustment of the band was required in 1 patient. No shunt thrombosis or shunt bandingrelated complications were noted.

Conclusions: Our formulas and surgical strategy offer a new approach to controlling excessive pulmonary blood flow in shunt-dependent circulations in an effective and predictable way. The best reproducibility was achieved in small, thin-walled shunts. This strategy was most effective in patients with pulmonary overcirculation without hemodynamic decompensation. (J Thorac Cardiovasc Surg 2016;152:1343-52)

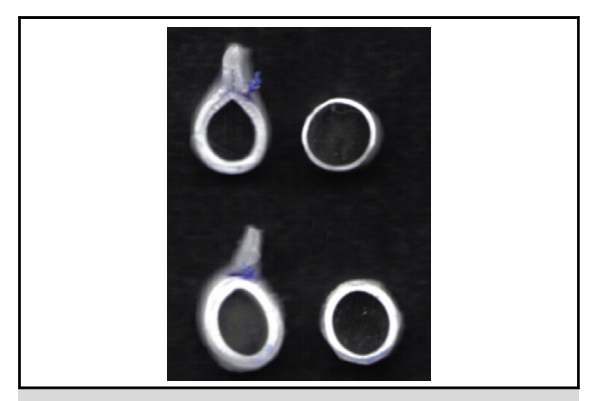

Banded and regular shunts in vitro.

Central Message

The effect of systemic-to-pulmonary artery shunt banding can be predicted more precisely based on theoretical considerations.

\section{Perspective}

Consideration of theoretical calculations and measurements improve the precision and reproducibility of banding procedures of systemic-to-pulmonary artery shunts. Simple, clinically applicable formulas can guide the surgeon to predictably alter pulmonary blood flow in the setting of high $\mathrm{Q}_{\mathrm{p}}: \mathrm{Q}_{\mathrm{s}}$. Early shunt banding in patients without hemodynamic deterioration leads to better hemodynamic stabilization.

See Editorial Commentary page 1353.

\footnotetext{
From The Division of Cardiovascular Surgery, The Labatt Family Heart Centre, The Hospital for Sick Children, and the Department of Surgery, University of Toronto, Toronto, Ontario, Canada.

Drs Atlin and Haller contributed equally to this work

Received for publication Nov 23, 2015; revisions received July 28, 2016; accepted for publication July 30, 2016

Address for reprints: Glen S. Van Arsdell, MD, Division of Cardiovascular Surgery, The Hospital for Sick Children, 555 University Ave, Toronto, Ontario, Canada M5G 1X8 (E-mail: glen.vanarsdell@sickkids.ca).

$0022-5223 / \$ 36.00$

Copyright (C) 2016 Published by Elsevier Inc. on behalf of The American Association for Thoracic Surgery

http://dx.doi.org/10.1016/j.jtcvs.2016.07.081
}

The creation of a systemic-to-pulmonary artery (SP) shunt is a common and important strategy for staged palliative surgery. ${ }^{1,2}$ The mortality associated with this procedure is

Scanning this QR code will take you to supplemental figures, tables, and video for this article.

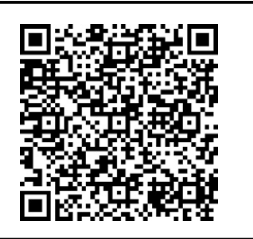




$$
\begin{aligned}
& \text { Abbreviations and Acronyms } \\
& \begin{aligned}
\mathrm{BT} & =\text { Blalock-Taussig } \\
\mathrm{ECMO} & =\text { extracorporeal membrane oxygenation } \\
\mathrm{PTFE} & =\text { polytetrafluoroethylene } \\
\mathrm{Q}_{\mathrm{p}} & =\text { pulmonary blood flow } \\
\mathrm{Q}_{\mathrm{s}} & =\text { systemic blood flow } \\
\mathrm{SP} & =\text { systemic to pulmonary artery }
\end{aligned}
\end{aligned}
$$

high compared with corrective procedures ${ }^{3,4}$ and especially high in patients weighing $<2.5 \mathrm{~kg}$. In low birth weight patients, mortality can reach $15.6 \%{ }^{3}$ Parallel perfusion of pulmonary and systemic circulation is a major contributor to early postoperative death. ${ }^{5}$ Mismatch between body weight and shunt size can result in excessive pulmonary blood flow, compromising systemic oxygen delivery. ${ }^{6}$ As the shunt size-to-body weight ratio increases, medical manipulation of systemic and pulmonary vascular resistance may be inadequate to sufficiently decrease pulmonary blood flow. ${ }^{7}$

Smaller shunts can be a solution, but are associated with a substantially increased risk of thrombosis and reintervention. ${ }^{8}$ Refined techniques for flow reduction have been described, including adjustable tourniquets, ${ }^{9}$ bands,${ }^{10}$ and removable vascular $\operatorname{clips}^{11,12}$; however, although these techniques can effectively downsize shunt diameter, no technique reported to date can be reliably predicted and reproduced. In an in vivo study, we tested the hypothesis that external bands can be applied to shunts to predictably reduce shunt size. Here we present a mathematical model for predicting the impact of changing shunt size on flow, and report the clinical use of banding.

\section{MATERIALS AND METHODS \\ Definition of Shunt Banding}

The surgical technique is similar to that used for banding branch pulmonary arteries. ${ }^{13}$ A 3- to 4-mm polytetrafluoroethylene (PTFE) graft is opened longitudinally and trimmed to a width of 2 to $5 \mathrm{~mm}$. The band is secured using 6-0 polypropylene sutures (Ethicon, Somerville, NJ) (Figure E1).

\section{Mathematical and Pathophysiological Aspects}

Calculation of flow through a tubular graft is subject to several restrictions. Ohm's law states that

$$
I=\frac{U}{R}
$$

where $I$ is blood flow through the graft, $U$ is the pressure difference across the graft, and $R$ is the resistance of the graft.

The band can be considered a resistor. Its actual position is negligible because, according to Kirchhoff's law, in-series resistors are added up independently of their sequence. Resistance increases with the length of the shunt and the banding; nevertheless, the length of the banding can be too short to substantially influence resistance. ${ }^{14}$
Hagen-Poiseuille's law states that

$$
\dot{V}=\frac{\pi r^{4} \Delta p}{8 \eta l}
$$

or, with regard to the graft's radius,

$$
r=\sqrt[4]{\frac{\dot{V} 8 \eta l}{\pi \Delta p}}
$$

where $r$ is the shunt radius, $V$ is the blood flow through the shunt, $\eta$ is a constant of viscosity, $l$ is the graft length, and $\Delta p$ is the pressure difference between systemic circulation and the pulmonary artery.

Because shunt banding focuses on increased resistance, the equation can be further solved as

$$
r=\sqrt[4]{\frac{8 \eta l}{\pi R_{\text {shunt }}}}
$$

where $R_{\text {shunt }}$ is shunt resistance. The lengths of the banding and the shunt are considered negligible, and blood viscosity, cardiac output, and systemic and pulmonary artery pressures are considered constant.With a known $Q_{p}: Q_{s}$, the ratio of $Q_{p \text { new }}$ to $Q_{p \text { old }}$ to achieve a balanced $Q_{p}: Q_{s}$ can be calculated as

$$
\frac{Q_{p}-\left(\frac{Q_{p}-Q_{s}}{2}\right)}{Q_{p}}
$$

This ratio defines the required reduction in pulmonary blood flow or the increase in resistance, and thus can be used to calculate the desired optimal radius, diameter, and circumference of the shunt in cases of $\mathrm{Q}_{\mathrm{p}}: \mathrm{Q}_{\mathrm{s}}$ mismatch (Figure 1):

$$
\begin{gathered}
r_{\text {new }}=r_{\text {old }} \sqrt[4]{\frac{Q_{p}-\left(\frac{Q_{p}-Q_{s}}{2}\right)}{Q_{p}}} \\
d_{\text {new }}=2 r_{\text {old }} \sqrt[4]{\frac{Q_{p}-\left(\frac{Q_{p}-Q_{s}}{2}\right)}{Q_{p}}}
\end{gathered}
$$

$$
c i r c_{\text {new }}=2 \pi r_{\text {old }} \sqrt[4]{\frac{Q_{p}-\left(\frac{Q_{p}-Q_{s}}{2}\right)}{Q_{p}}}
$$

\section{In Vitro Morphometric Shunt Banding Model}

Sixteen thin-walled and regular-walled PTFE grafts of 3- to 10-mm internal diameter were banded using a PTFE strip (Figure 2 and Table E1). Thin-walled grafts (W.L. Gore \& Associates, Flagstaff, Ariz) with internal diameters of $3,3.5,4,5,6,7,8$, and $10 \mathrm{~mm}$ and a median thickness of $0.45 \mathrm{~mm}$ (range, $0.43-0.65 \mathrm{~mm}$ ) were studied. In addition, 2 standardwalled grafts (Bard Peripheral Vascular, Tempe, Ariz) with internal diameters of $3 \mathrm{~mm}$ and $3.5 \mathrm{~mm}$ (mean thickness, $0.58 \mathrm{~mm}$; range, $0.53-0.63 \mathrm{~mm}$ ) were analyzed. Shunts were divided into 2 groups according to size (small shunt, 3-5 mm; large shunt, 6-10 mm). The small shunt group served as a reference for correlation with real patients with a shunt. Although the large shunt is rarely used in a clinical setting, this group was examined for proof of principle.

Banding aimed at achieving a reduction in internal shunt diameter of 0.25 or $0.50 \mathrm{~mm}$. These values were chosen for surgical reproducibility. 


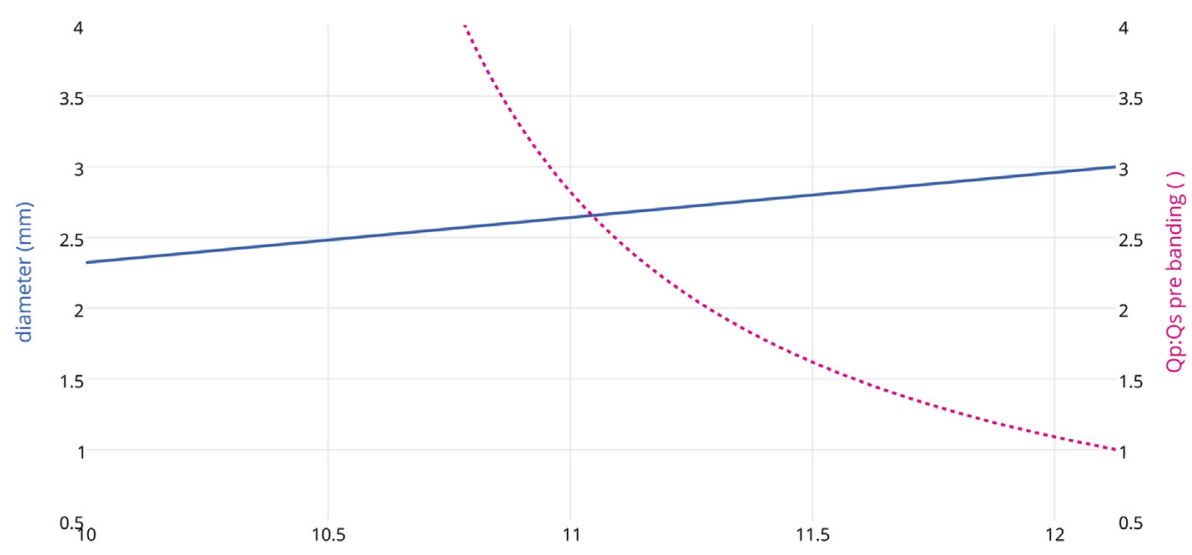

A

length of band $(\mathrm{mm})$

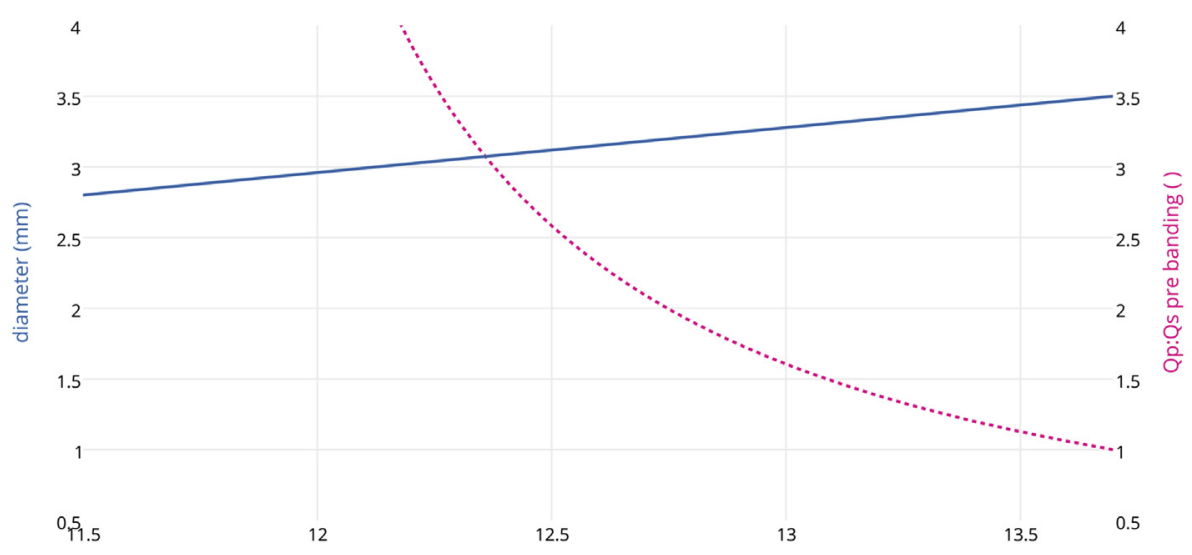

B

length of band $(\mathrm{mm})$

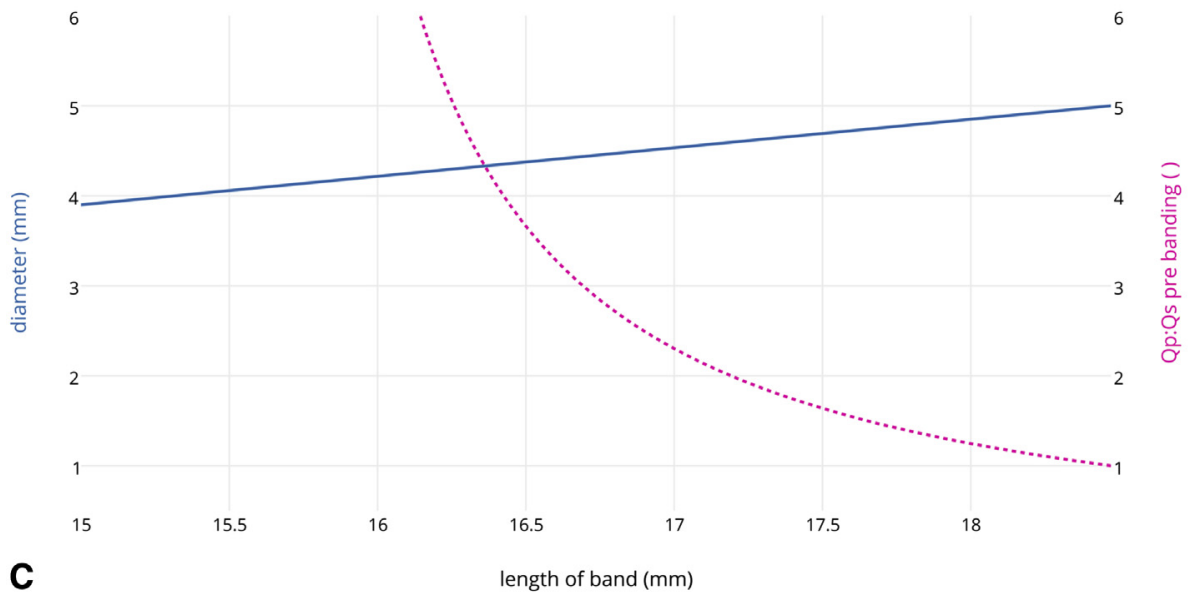

FIGURE 1. Physiological impact of length of the band for common thin-walled shunt sizes. (A) $3 \mathrm{~mm}$. (B) $3.5 \mathrm{~mm}$. (C) $5 \mathrm{~mm}$. The solid line represents the length of the banding in relation to the desired diameter. The dotted line represents the length of the banding in relation to the prebanding $\mathrm{Q}_{\mathrm{p}}$ : $\mathrm{Q}_{\mathrm{s}}$. This figure can be used to easily assess the length of the band needed for reduction to a certain shunt diameter ( $x$-value of the solid line at respective diameter), as well as to get an estimate of the physiological impact of the banding ( $y$-value of the dotted line at respective band length). $Q_{p}$, Pulmonary blood flow; $Q_{s}$, systemic blood flow. 


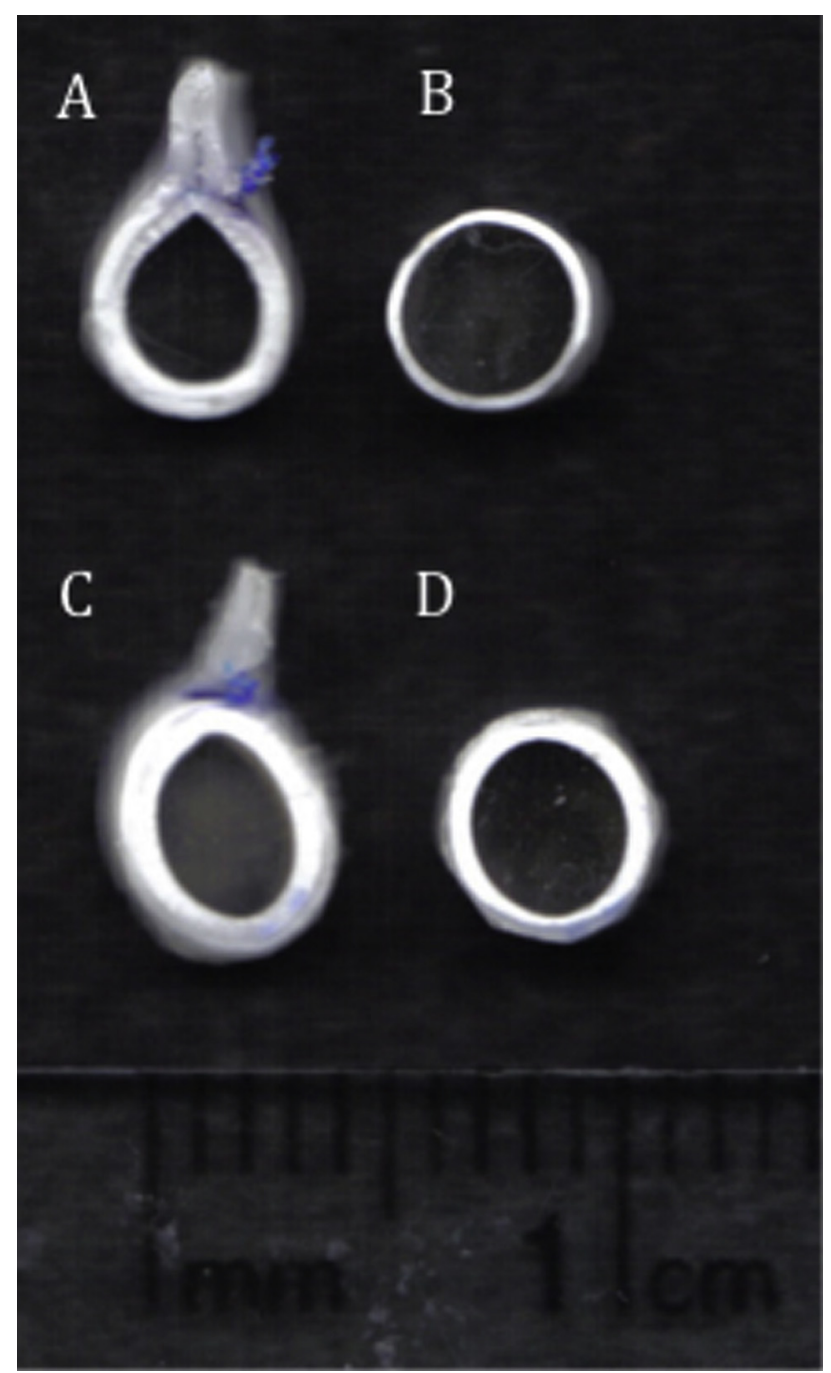

FIGURE 2. Morphometric shunt cross-sections. (A) 3.5-mm thin-walled Blalock-Taussig (BT) shunt banded to $3 \mathrm{~mm}$. (B) 3.5-mm thin-walled BT shunt. (C) $3.5-\mathrm{mm}$ regular-walled BT shunt banded to $3 \mathrm{~mm}$. (D) $3.5-\mathrm{mm}$ regular-walled BT shunt.

Preliminary testing showed that cutting PTFE to an accuracy of $0.5 \mathrm{~mm}$ is feasible and can be performed with adequate precision. A change in circumference of $0.5 \mathrm{~mm}$ reduces the diameter from $3 \mathrm{~mm}$ to $2.84 \mathrm{~mm}$, from $4 \mathrm{~mm}$ to $3.84 \mathrm{~mm}$, and from $5 \mathrm{~mm}$ to $4.84 \mathrm{~mm}$. Overbanding was defined as a measured relative reduction in diameter above the predicted relative reduction; underbanding, as a measured relative reduction below the predicted relative reduction.

Band length in general can be calculated as

$$
l_{\text {band }}=\pi\left(d_{\text {new }}+2 t_{\text {wall }}\right)
$$

where $l$ is band length, $d$ is the desired new internal diameter, and $t$ is shunt wall thickness (Table 1). Band length also can be calculated as

$$
l_{\text {band }}=2 \pi\left(r_{\text {old }}+t_{\text {wall }}\right) \sqrt[4]{\frac{Q_{p}-\left(\frac{Q_{p}-Q_{s}}{2}\right)}{Q_{p}}}
$$

The relationship between formulas (f.9) and (f.10) is illustrated in Figure 1.
To simulate normal graft expansion at physiological pressures, banded shunts were fixed in paraffin wax while pressurized with normal saline at 55 to $60 \mathrm{~mm} \mathrm{Hg}$. Paraffin-fixed shunts were filled with vinyl polysiloxane (Clinician's Choice, London, Ontario, Canada). Freehand cross-sections (median, 8; range, 5-15) were obtained from banded and nonbanded shunts using a surgical scalpel. Cross-sectional area was measured from digitalized images using conventional graphic software (Photoshop CS5; Adobe Systems, San Jose, Calif). Internal diameter could be calculated owing to the fixed image aspect ratios. Because the band often caused a teardrop shape with the acute angle at the band's anastomosis, the diameter was averaged from cross-sectional area measurements. The predicted percent reduction was derived by

$$
\frac{\frac{l_{\text {band }}}{\pi}-2 t_{\text {wall }}}{d_{\text {shunt }}} \times 100
$$

The percentage of reduction achieved was calculated with

$$
\frac{d_{m \_n e w}}{d_{m \_s h u n t}} \times 100
$$

where $d_{m}$ is the respective value measured prebanding and postbanding.

\section{Clinical Experience}

Our institution's Research Ethics Board approved this retrospective analysis and waived patient consent. The presented concept has been in clinical use since 2008. All patients who received an SP shunt between 2008 and 2012 were reviewed $(n=123)$. Patients who underwent SP shunt banding were identified from our cardiovascular surgery database $(n=8$; $6.5 \%$ ). Medical records, critical care records, and angiograms were reviewed. The effectiveness of SP shunt banding was evaluated based on hemodynamic and laboratory parameters before and after banding. $Q_{p}: Q_{s}$ was calculated based on abstractions of Fick's principle:

$$
\frac{Q_{p}}{Q_{s}}=\frac{\text { Sat }_{\text {Aorta }}-\text { Sat }_{\text {mixed_venous }}}{\text { Sat }_{\text {pulmunary_veins_ }}-\text { Sat }_{\text {pulmonary_artery }}}
$$

Pulmonary artery saturation was considered equal to systemic arterial saturation. Pulmonary venous saturation was assumed to be $95 \%$.

\section{Statistical Analysis}

For the morphometric experiment, 2 main aspects were analyzed: (1) the discrepancy between the measured nonbanded shunt diameter and the manufacturer's specifications and (2) a comparison of achieved banded shunt diameter and calculated banded shunt diameter. Data are presented as mean \pm standard deviation unless noted otherwise. Comparisons were performed using a paired-samples $t$ test. Pearson's correlation was used to compare calculated and measured banded shunt diameters. Statistical significance was assumed at $P<.05$. All statistical analyses were performed with SAS version 9.2 (SAS Institute, Cary, NC).

\section{RESULTS \\ Morphometric Measurements}

We compared the diameters provided by the shunt manufacturers with our measurements (Tables 2 and E2). The manufacturers' specifications served as reference values for evaluating the correctness and reproducibility of shunt fixation and measurement. In the small shunt group, the measured diameters were significantly smaller than the manufacturers' specifications (mean, $3.49 \pm 0.57 \mathrm{~mm}$ vs $3.55 \pm 0.61 \mathrm{~mm} ; P=.029 ; \mathrm{n}=12$ ). This discrepancy could be attributed to the fact that the small shunt group included both thin- and regular-walled shunts. The regular-walled 
TABLE 1. Sample band lengths for thin-walled small shunts

\begin{tabular}{lccc}
\hline $\begin{array}{c}\text { Original shunt } \\
\text { diameter, mm }\end{array}$ & $\begin{array}{c}\text { Wall thickness, } \\
\text { mm; } \boldsymbol{t}_{\text {wall }}\end{array}$ & $\begin{array}{c}\text { Predicted decrease in } \\
\text { diameter, mm }\end{array}$ & $\begin{array}{c}\text { Banded shunt } \\
\text { diameter, mm; } \boldsymbol{d}_{\text {new }}\end{array}$ \\
\hline 3.00 & 0.43 & 0.50 & 2.50 \\
3.00 & 0.43 & 0.25 & 2.75 \\
3.50 & 0.43 & 0.50 & 3.00 \\
3.50 & 0.43 & 0.25 & 3.25 \\
4.00 & 0.46 & 0.50 & 3.50 \\
4.00 & 0.46 & 0.25 & 3.75 \\
5.00 & 0.44 & 0.50 & 10.6 \\
\hline
\end{tabular}

shunts were more rigid than the thin-walled grafts with paraffin wax injection. Furthermore, severe narrowing, such as a reduction in diameter from $5 \mathrm{~mm}$ down to $3.75 \mathrm{~mm}$, caused unreliable measurements. Therefore, the regular-walled shunts and 1 of the thin-walled shunts were excluded from the remainder of our analysis. Repeat analysis of the thin-walled grafts showed comparable values between the measured diameters and manufacturers' specifications (mean, $3.64 \pm 0.65 \mathrm{~mm}$ vs $3.71 \pm 0.70 \mathrm{~mm} ; P=.097 ; \mathrm{n}=7$ ).

In the large shunt group, the $10-\mathrm{mm}$ shunt had to be excluded, because fixation could not be performed properly owing to the large size. The measured diameters were significantly smaller than the manufacturers' specifications (mean, $6.73 \pm 0.99 \mathrm{~mm}$ vs $7.00 \pm 1.00 \mathrm{~mm} ; P=.020$; $\mathrm{n}=3$ ), owing in part to inadequate expansion by paraffin injection.

Our data indicate that small, thin-walled shunts can be reliably fixed and measured. The results for both large-sized and regular-walled shunts need to be interpreted with caution, however.

\section{Reproducibility of Shunt Banding}

The diameters of banded small, thin-walled shunts were comparable to the targeted diameters (mean, $3.34 \pm 0.60 \mathrm{~mm}$ vs $3.32 \pm 0.67 \mathrm{~mm} ; P=.834 ; \mathrm{n}=7)$. There was a strong correlation between the measured and calculated diameters $(r=0.953 ; P=.001)$ (Figure E1). Five of 7 shunts $(71.4 \%)$ were underbanded, and the other 2 were overbanded (Table 2). The overbanded shunts tended to be overbanded to a greater degree than the underbanding in the underbanded shunts (mean, $0.05 \pm 0.03 \mathrm{~mm}$ vs $0.03 \pm 0.04 \mathrm{~mm}$ ); however, this tendency was not statistically significant $(P=.281)$. Diameters of the banded regions were significantly smaller than those of the nonbanded regions (mean, $3.34 \pm 0.60 \mathrm{~mm}$ vs $3.64 \pm 0.65 \mathrm{~mm} ; P=.001 ; \mathrm{n}=7)$, demonstrating that banding produced a reduction in diameter. The relative reduction rates of all thin-walled shunts were comparable to the predicted values (mean, $0.10 \pm 0.04$ vs $0.07 \pm 0.03 ; P=.112 ; \mathrm{n}=10)$; however, the rates of relative reduction of the regular-walled shunts were consistently and significantly lower compared with the predicted values (mean, $0.08 \pm 0.02 \mathrm{~mm}$ vs $1.11 \pm 0.04 \mathrm{~mm} ; P=.006 ; \mathrm{n}=4)$, indicating difficulty in effectively banding the regular-walled shunts (Table E2).

\section{Banding and Shunt Flow}

The formulas used to reduce a known $\mathrm{Q}_{\mathrm{p}}: \mathrm{Q}_{\mathrm{s}}$ ratio to balance pulmonary and systemic blood flow (f.6-f.8) can be applied retrospectively to those patients with a known $\mathrm{Q}_{\mathrm{p}}: \mathrm{Q}_{\mathrm{s}}$. Figure 1 can be used to readily assess the desired length of the band by choosing the $x$-value at the respective $\mathrm{Q}_{\mathrm{p}}: \mathrm{Q}_{\mathrm{s}}$ of the dotted line on the graph.

TABLE 2. Calculated and predicted parameters for banded thin-walled shunts

\begin{tabular}{|c|c|c|c|c|c|c|c|c|}
\hline $\begin{array}{r}\text { Manufacturer } \\
\text { shunt size, mm }\end{array}$ & $\begin{array}{c}\text { Measured, mm, } \\
\text { mean } \pm \text { SD }\end{array}$ & $\mathbf{n}$ & $\begin{array}{c}\text { Predicted } \\
\text { banding, } \mathbf{m m}\end{array}$ & $\begin{array}{c}\text { Measured banding, } \\
\text { mm, mean } \pm \text { SD }\end{array}$ & $\mathbf{n}$ & $\begin{array}{l}\text { Predicted relative } \\
\text { reduction, \% }\end{array}$ & $\begin{array}{l}\text { Measured relative } \\
\text { reduction, \% }\end{array}$ & Interpretation \\
\hline 3.0 & $2.95 \pm 0.03$ & 12 & 2.50 & $2.71 \pm 0.27$ & 8 & 16.67 & 8.15 & - \\
\hline 3.0 & $2.95 \pm 0.05$ & 7 & 2.75 & $2.54 \pm 0.16$ & 7 & 8.33 & 14.0 & + \\
\hline 3.5 & $3.63 \pm 0.10$ & 13 & 3.00 & $3.36 \pm 0.16$ & 8 & 14.29 & 7.37 & - \\
\hline 3.5 & $3.41 \pm 0.06$ & 11 & 3.25 & $3.22 \pm 0.17$ & 9 & 7.14 & 5.41 & - \\
\hline 4.0 & $3.88 \pm 0.03$ & 11 & 3.50 & $3.56 \pm 0.09$ & 10 & 12.50 & 8.17 & - \\
\hline 4.0 & $3.84 \pm 0.02$ & 6 & 3.75 & $3.65 \pm 0.13$ & 10 & 6.25 & 4.96 & - \\
\hline 5.0 & $4.84 \pm 0.03$ & 7 & 4.50 & $4.33 \pm 0.09$ & 5 & 10.00 & 10.67 & + \\
\hline 6.0 & $5.79 \pm 0.05$ & 8 & 5.50 & $5.33 \pm 0.19$ & 7 & 8.33 & 7.81 & - \\
\hline 7.0 & $6.66 \pm 0.07$ & 10 & 6.50 & $6.25 \pm 0.09$ & 7 & 7.14 & 6.20 & - \\
\hline 8.0 & $7.75 \pm 0.11$ & 10 & 7.50 & $7.66 \pm 0.14$ & 7 & 6.25 & 1.31 & - \\
\hline
\end{tabular}

SD, Standard deviation; +, overbanded; -, underbanded. 
TABLE 3. Patient profiles

\begin{tabular}{|c|c|c|c|c|c|c|c|c|}
\hline Patient & Diagnosis & $\begin{array}{l}\text { Age at first } \\
\text { operation, d }\end{array}$ & $\begin{array}{c}\text { Age at } \\
\text { banding, } d\end{array}$ & $\begin{array}{c}\text { Weight, } \\
\text { kg }\end{array}$ & $\begin{array}{c}\text { Shunt } \\
\text { size, mm }\end{array}$ & $\begin{array}{c}\text { Shunt } \\
\text { type }\end{array}$ & Outcome & $\begin{array}{l}\text { Age at latest } \\
\text { procedure, d }\end{array}$ \\
\hline 1 & TA, TGA, VSD, PS & 0 & 0 & 3.45 & 3.5 & Central & Fontan completed & 184 \\
\hline 2 & PA, MA, TGA, VSD & 0 & 1 & 3.00 & 3.5 & Central & Death after stage I & 17 \\
\hline 3 & $\begin{array}{l}\text { RAI, unbalanced AVSD, } \\
\text { nonconfluent PA }\end{array}$ & 86 & 86 & 3.80 & 3.5 & $\mathrm{mBT}$ & Death after stage I & 112 \\
\hline 4 & TA, DOLV & 8 & 12 & 3.70 & 3.5 & $\mathrm{mBT}$ & Awaiting Fontan & 201 \\
\hline 5 & HLHS, IAS & 2 & 17 & 3.10 & 3.5 & $\mathrm{mBT}$ & Fontan completed & 1485 \\
\hline 6 & DILV, TGA, PS & 6 & 6 & 2.70 & 3.5 & $\mathrm{mBT}$ & Awaiting Fontan & 176 \\
\hline 7 & HLHS, AA & 12 & 19 & 2.50 & 5.0 & Sano & Awaiting stage II & 19 \\
\hline 8 & PA, VSD & 80 & 80 & 2.00 & 3.5 & $\mathrm{mBT}$ & Death after stage I & 91 \\
\hline
\end{tabular}

$T A$, Tricuspid atresia; $T G A$, transposition of the great arteries; $V S D$, ventricular septal defect; $P S$, pulmonary stenosis; $P A$, pulmonary atresia; $M A$, mitral atresia; $R A I$, right atrial isomerism; $A V S D$, atrioventricular septal defect; $m B T$, modified Blalock-Taussig; $D O L V$, double-outlet left ventricle; $H L H S$, hypoplastic left heart syndrome; IAS, intact atrial septum; $D I L V$, double-inlet left ventricle; $A A$, aortic atresia.

\section{Clinical Experience}

Among the 123 patients who received a SP shunt between January 2008 and February 2012, 8 (6.5\%) underwent shunt banding (Table 3 and Video 1). Shunt types were modified Blalock-Taussig (BT) in 5 patients, central in 2 patients, and Sano in 1 patient. The median age at banding was 14.5 days (range, 0-86 days), and the median weight at banding was $3.05 \mathrm{~kg}$ (range, 2.0-3.8 kg). Patient profiles are presented in Table 3.

Three patients $(38 \%)$ underwent shunt banding at the time of the index procedure. Two patients showed immediate and significant signs of excessive pulmonary blood flow, with high saturation values and intractable low systemic pressure after shunt placement. After banding, 1 of these patients exhibited improved hemodynamics, with

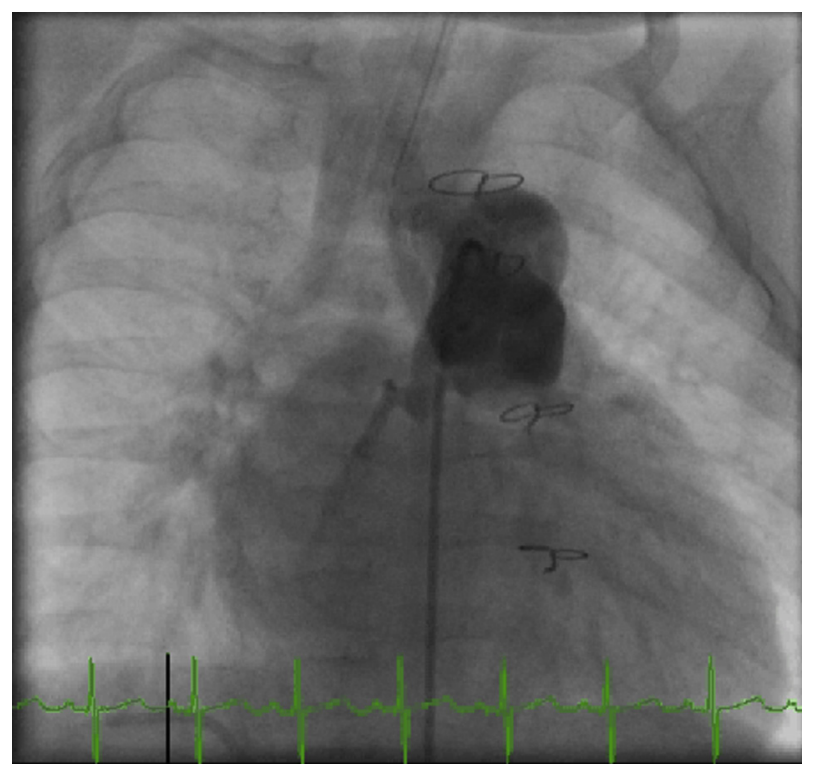

VIDEO 1. Angiography delineating a banded Blalock-Taussig shunt. Video available at: http://www.jtcvsonline.org/article/S0022-5223(16) 31069-8/addons. higher diastolic blood pressure and lower arterial saturation; however, the other patient showed initial signs of ventricular dysfunction with low diastolic systemic pressure, resulting in insufficient coronary perfusion. In this patient, banding led to the desired adjustment of $\mathrm{Q}_{\mathrm{p}}: \mathrm{Q}_{\mathrm{s}}$, but coronary ischemia persisted.

Five patients $(62 \%)$ underwent shunt banding in the intensive care unit. In 3 of these patients, the banding was performed for pulmonary overcirculation at the time of chest closure with stable hemodynamics and metabolism. Two of these patients exhibited adequate hemodynamic changes after band application, whereas the other patient did not show any significant improvement. The remaining 2 patients underwent shunt banding as a rescue procedure for low cardiac output due to pulmonary overcirculation. One of these patients could be temporarily stabilized with banding, but sudden cardiopulmonary collapse necessitated extracorporeal membrane oxygenation (ECMO) 2 days later. The other patient showed signs of systemic malperfusion immediately after shunt placement, followed by cardiac arrest. Circulation could be reestablished, and the shunt was banded, but ECMO support was required after recurrent profound desaturations and cardiac arrest.

Overall, 5 of 8 patients $(62.5 \%)$ demonstrated some clinical hemodynamic improvement. Arterial saturation showed a significant mean decrease of $5.50 \pm 5.50$ $(P=.026)$, and $\mathrm{pH}$ demonstrated a significant mean decrease of $0.05 \pm 0.03(P=.002) . \mathrm{Q}_{\mathrm{p}}: \mathrm{Q}_{\mathrm{s}}$ decreased significantly, by a mean of $1.07 \pm 0.62(P=.004)$. Details are presented in Table 4 and Figure 3.

\section{Complications}

One episode of significant desaturation related to shunt banding occurred that required debanding and reapplication of the band. After rebanding, no episode of significant desaturation related to the band was noted. All patients received anticoagulation therapy with unfractionated 
TABLE 4. Patient hemodynamic parameters

\begin{tabular}{|c|c|c|c|c|c|c|c|c|}
\hline Patient & sBP, mm Hg & dBP, $\mathrm{mm} \mathrm{Hg}$ & $\mathrm{SaO}_{2}, \%$ & Mixed $\mathrm{SvO}_{2}, \%$ & $\mathrm{paO}_{2}, \mathrm{~mm} \mathrm{Hg}$ & $\mathrm{paCO}_{2}, \mathrm{~mm} \mathrm{Hg}$ & pH & $\mathbf{Q}_{\mathrm{p}}: \mathbf{Q}_{\mathrm{s}}$ \\
\hline \multicolumn{9}{|c|}{ Prebanding } \\
\hline 1 & 49 & 21 & 89 & 77 & 67 & 45 & 7.30 & 2.0 \\
\hline 2 & 52 & 26 & 83 & 65 & 45 & 35 & 7.33 & 1.5 \\
\hline 3 & 50 & 17 & 71 & 29 & 43 & 58 & 7.21 & 1.7 \\
\hline 4 & 74 & 35 & 81 & 52 & 47 & 45 & 7.44 & 2.0 \\
\hline 5 & 74 & 34 & 86 & 50 & 52 & 36 & 7.28 & 4.0 \\
\hline 6 & 51 & 25 & 79 & 34 & 21 & 46 & 7.35 & 2.8 \\
\hline 7 & $*$ & $*$ & 70 & 42 & 34 & 59 & 7.30 & 1.1 \\
\hline 8 & NA & NA & 99 & 76 & 180 & 39 & 7.38 & NA \\
\hline \multicolumn{9}{|c|}{ Postbanding } \\
\hline 1 & 49 & 26 & 73 & 56 & 40 & 43 & 7.27 & 0.7 \\
\hline 2 & 51 & 26 & 78 & 59 & 43 & 41 & 7.26 & 1.1 \\
\hline 3 & 59 & 32 & 70 & 55 & 40 & 44 & 7.16 & 0.6 \\
\hline 4 & 67 & 32 & 71 & 39 & 43 & 55 & 7.33 & 1.3 \\
\hline 5 & 90 & 34 & 80 & 42 & 47 & 43 & 7.26 & 2.5 \\
\hline 6 & 63 & 31 & 79 & 68 & 32 & 48 & 7.29 & 0.7 \\
\hline 7 & $*$ & $*$ & 64 & 42 & 38 & 69 & 7.26 & 0.7 \\
\hline 8 & NA & NA & 99 & 74 & 166 & 38 & 7.36 & NA \\
\hline
\end{tabular}

$\overline{s B P}$, Systolic blood pressure; $d B P$, diastolic blood pressure; $\mathrm{SaO}_{2}$, arterial oxygen saturation; mixed $\mathrm{SvO}_{2}$, mixed venous saturation; $\mathrm{paO}_{2}$, partial pressure of oxygen; $\mathrm{paCO}_{2}$, partial pressure of carbon dioxide; $N A$, not applicable (values/calculations do not apply because the patient was on extracorporeal membrane oxygen support). $*$ Data not available.

heparin infusion, followed by subcutaneous low molecular weight heparin injection until stage II palliation, in accordance with our protocol for nonbanded shunt patients. There were no cases of shunt thrombosis among hospital
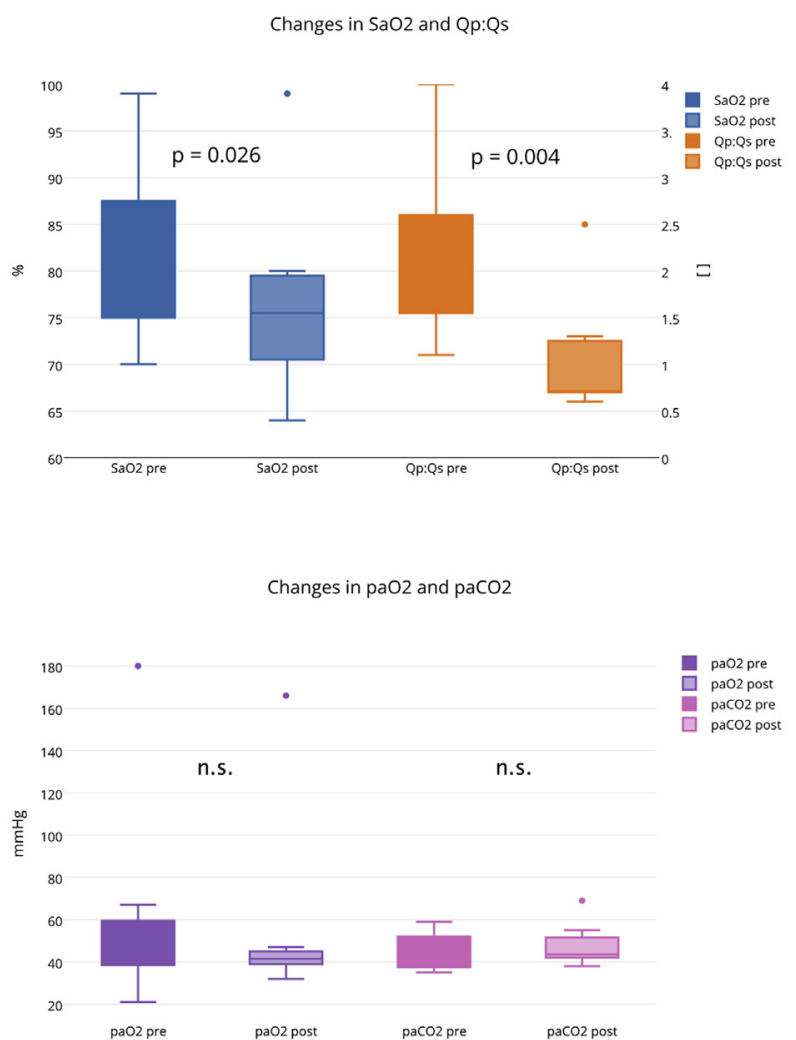

survivors. Figure E2 shows an excised banded BT shunt at stage II palliation demonstrating no thrombus in the lumen. Figure E3 presents angiograms of a banded shunt showing no discrete caliber changes.
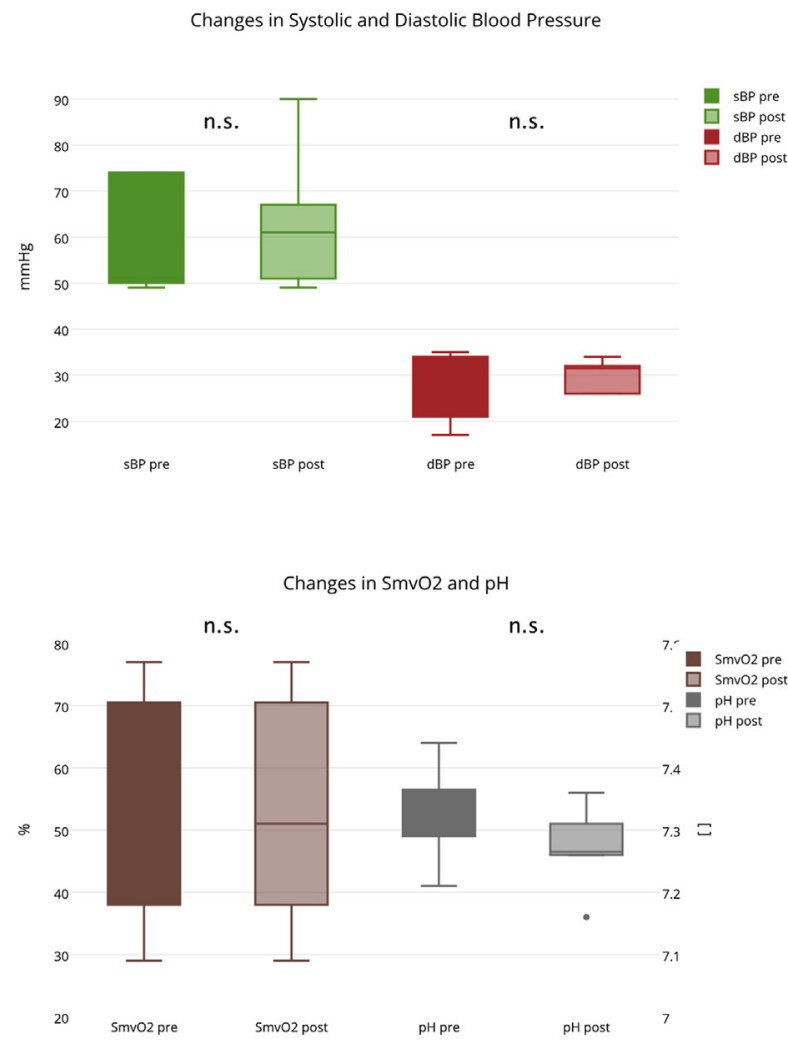

FIGURE 3. Changes in hemodynamic and blood gas values. $\mathrm{SaO}_{2}$, Arterial oxygen saturation; $Q_{p}$, pulmonary blood flow; $Q_{s}$, systemic blood flow; n.s., not significant; $s B P$, systolic blood pressure; $d B P$, diastolic blood pressure; $\mathrm{paO}_{2}$, partial pressure of oxygen; $\mathrm{paCO}_{2}$, partial pressure of carbon dioxide; $\mathrm{SmVO}_{2}$, mixed venous saturation. 


\section{DISCUSSION}

Balancing systemic and pulmonary perfusion is of major importance in the acute postoperative management of patients with a shunt-dependent circulation. Therapeutic respiratory acidosis with relatively high carbon dioxide and systemic afterload reduction therapy generally achieves the goal of balanced $\mathrm{Q}_{\mathrm{p}}: \mathrm{Q}_{\mathrm{s}}$; however, we often face challenges of compromised systemic oxygen delivery due to pulmonary overcirculation that are resistant to conventional medical therapy.

This report delineates the theoretical background of shunt banding and its relationship to clinical data. It demonstrates the precision of theoretical, in vitro, and clinical measurements, as well as the efficacy and reproducibility of the surgical technique to reduce pulmonary shunt flow in a predictable manner. Clinical data are somewhat mixed, with clinical improvement seen in 5 of 8 patients $(62 \%)$, who were mostly hemodynamically stable at the time of banding. Not surprisingly, shunt banding as a salvage procedure did not dramatically alter the clinical course.

\section{Reproducibility of Shunt Banding}

In vitro measurements showed that the formula used for shunt banding (f.9) could reliably narrow the shunt lumen in small, thin-walled shunts. All but 2 measurements showed a less-than-expected reduction in the measured diameter. This can be explained by the elasticity of the band itself. Although the calculation is theoretically correct, the mechanical properties of the shunt and the band are not considered. Thus, the smaller changes in diameter in standard-walled shunts may be due to the greater stiffness of the material, which results in greater stretching of the band. The calculations could be further improved with constants reflecting the band elasticity and shunt rigidity. The results for large or regular-walled shunts may be less reliable, given that our baseline measurements showed considerable differences from the manufacturers' specifications.

\section{Banding and Shunt Flow}

Obviously, minimal changes in diameter of a shunt impact the pulmonary blood flow substantially. ${ }^{7}$ It is therefore important to understand the physiological impact of the intended reduction. Our theoretical model can be used to either calculate the desired reduction in shunt diameter based on the initial $Q_{p}: Q_{s}$ or to demonstrate the effect of a defined banding with regard to $\mathrm{Q}_{\mathrm{p}}: \mathrm{Q}_{\mathrm{s}}$ (Figure 1). To cover the most common clinical scenarios, calculations for $\mathrm{Q}_{\mathrm{p}}: \mathrm{Q}_{\mathrm{s}}$ of 1.5 and 2.5 exemplify how small the necessary changes are. In the setting of a $3.5-\mathrm{mm}$ shunt with $\mathrm{Q}_{\mathrm{p}}: \mathrm{Q}_{\mathrm{s}}$ of 1.5 , the optimal diameter would be 3.34 $\mathrm{mm}$ - that is, a reduction of $0.16 \mathrm{~mm}$ or a calculated band length of $13.09 \mathrm{~mm}$. If the $\mathrm{Q}_{\mathrm{p}}: \mathrm{Q}_{\mathrm{s}}$ is 2.5 , then the desired diameter would be $3.20 \mathrm{~mm}$, leading to a reduction of $0.30 \mathrm{~mm}$, or a calculated band length of $12.53 \mathrm{~mm}$. The difference between the respective bands is thus $0.57 \mathrm{~mm}$. As mentioned earlier, cutting PTFE to an accuracy of $0.5 \mathrm{~mm}$ is feasible; however, to be absolutely precise, the necessary changes may instead require finer tuning, much as in the case of traditional banding of the pulmonary artery. It is intriguing that reducing a $3.5-\mathrm{mm}$ shunt to a diameter of $3.25 \mathrm{~mm}$, as done in our clinical setting, is a strikingly close estimate of the theoretical result of $3.26 \mathrm{~mm}$ in the setting of a $\mathrm{Q}_{\mathrm{p}}: \mathrm{Q}_{\mathrm{s}}$ of 2. With a more appropriate shunt size-to-body weight ratio, little deviation from the theoretically optimal diameter may very well be compensated for by conservative approaches to stabilizing hemodynamics.

\section{Clinical Experience}

Correlation of theoretical calculations and in vitro measurements with clinical experience is crucial. Application of the model in our patients has proven its feasibility. We used the shunt banding strategy in three clinical indications. The first indication was obvious pulmonary overcirculation with maintained cardiac output. The second indication was to improve systemic output in the setting of pulmonary overcirculation in patients with stable but borderline systemic oxygen delivery. The last indication was a salvage banding in an attempt to avoid mechanical circulatory support in the setting of seriously low cardiac output. Four out of 5 patients $(80 \%)$ who received shunt banding while maintaining systemic output improved hemodynamically after shunt banding. In acutely decompensated patients with insufficient cardiac output, shunt banding could not improve or only temporarily improve hemodynamic status. This is not necessarily an effect of insufficient banding or related to incorrect calculations, but rather a consequence of the deteriorated circulation with diminished total cardiac output. Our preliminary clinical experience indicates that early implementation of this strategy works best to prevent irreversible $\mathrm{Q}_{\mathrm{p}}: \mathrm{Q}_{\mathrm{s}}$ mismatch.

There are differences in physiology directly after weaning of extracorporeal circulation compared with the late postoperative period. Pulmonary vascular resistance is expected to decrease with time. Therefore, the timing of shunt banding reflects 2 distinct clinical scenarios. Early banding may be a truly "anatomic" effect of shunt-body weight mismatch, necessitating immediate intervention. Late overcirculation may instead be a physiological result of decreasing pulmonary vascular resistance, disequilibrating the balance of pulmonary and systemic circulation with an initially appropriately sized shunt. We do not believe that the underlying reason for excessive pulmonary blood flow influences the banding strategy itself; rather, it can be expected that patients with an early banding procedure show a second increase 
in pulmonary blood flow after banding. Whether this should be addressed by tighter initial bands should be the focus of further studies.

In very small neonates $(<2.5 \mathrm{~kg})$ with the greatest shunt-body size mismatch, prophylactic banding may be an appealing strategy. A primary downsizing of a 3.5-mm shunt to $3.25 \mathrm{~mm}$ may have significant clinical benefits with regard to preventing significant pulmonary overcirculation, as well as preventing chronic volume overload to the systemic ventricle. This strategy remains to be clinically evaluated; nonetheless, we are moving toward placing a $3.5-\mathrm{mm}$ shunt with a band as opposed to a 3-mm shunt that has a higher rate of shunt-related reinterventions. $^{2}$

\section{Clinical Pertinence and Perspective}

Currently used techniques to reduce shunt diameter have a lack of accuracy in reducing shunt size. ${ }^{9,11,12}$ All rely on feedback of hemodynamic monitoring. It seems evident that an individual approach to each patient's hemodynamics is more reliable. Altering the banding simply by roughly estimating the amount needed seems to be imprecise and inadequate. Furthermore, the use of clips and tourniquets leads to a rather complex shape of the narrowed part, making it even more difficult to predict the effect. The formulas provided here accurately predict shunt diameter.

The use of PTFE as banding material minimizes the risk of shunt damage. Furthermore, it ensures a reduction in diameter without altering the original shape substantially. It is advantageous that PTFE can be balloon-dilated gradually, whereas clips can only be removed completely. Inflatable adjustable bands could potentially overcome this problem; however, for now their use is limited to shunts larger than $3.5 \mathrm{~mm} .{ }^{10}$ This is a major limitation, because patients at greatest risk for temporary pulmonary overcirculation are neonates requiring small shunts. ${ }^{3}$ Shunts with a screw plunger resistor mechanism as described in a porcine model can be used only if the device is directly accessible. ${ }^{15}$

One potential disadvantage of external narrowing (ie, band, clip, or tourniquet) is an increased risk of shunt thrombosis. A local deformity of the shunt created by a flow-limiting material inevitably creates turbulence in the lumen, potentially inducing thrombus formation. Unlike a clip on a Sano shunt, which is commonly used as a temporary measure, our banding strategy is mainly intended to remain until the subsequent surgery. The important difference between a PTFE band and a clip is that a PTFE band provides relatively smooth transition from the nonbanded area to the banded area without obvious local deformity. In our clinical experience, we have encountered no episodes of shunt thrombosis. It will be important to study the rate of shunt thrombosis in a larger patient cohort in the future.

\section{Limitations}

The measured internal diameter did not match the manufacturers' specifications for regular-walled and large shunts. This may be the result of inadequate fixation, unequal distribution of paraffin wax, or different assessment techniques. We assume that the greater stiffness of thicker shunt walls and the larger diameters interfered with uniform fixation.

Calculations are always approximations of complex physiological processes. We are well aware that shunt flow is determined not only by the shunt itself, but also by systemic and pulmonary resistance, cardiac output, shunt position, and indirectly by ventilation parameters, laboratory values, medications, and many other factors. Nevertheless, the formulas reported herein can provide insight into the effects of shunt banding and guide surgical intervention. The formulas are not expected to be absolutely precise. Instead, these calculations provide a tool to add reproducibility and predictability to the banding procedure. They respect neither the purely systolic antegrade pulmonary blood flow nor the regurgitation seen in Sano shunts. Growth of the pulmonary artery during interstage and its effect on pulmonary blood flow are also not considered in the formulas. Thus, the Sano shunts can be expected to respond more sensitively to banding, although our data are not sufficient to prove this assumption.

Our sample size with regard to the numbers of both shunts and patients is relatively small. Owing to the retrospective nature of our clinical analysis, the timing of hemodynamic and blood gas analyses varies; therefore, the data might not exactly reflect the immediate effect of the procedure.

\section{CONCLUSIONS}

The formulas and surgical strategy discussed herein offer a new approach to controlling excessive pulmonary blood flow in shunt-dependent circulation in an effective and predictable way. This strategy is most effective in patients with pulmonary overcirculation without considerable decompensation. A larger study population and a prospective assessment will be needed to further strengthen these results. Investigations also may focus on predicting the optimal size of a shunt before initial implantation.

\section{Conflict of Interest Statement}

The authors have nothing to disclose with regard to commercial support.

We thank Dariusz Mroczek, Taras Masnyi, Greg Patterson, and Carl Granger for assistance in preparing and measuring the shunts.

\section{References}

1. Wilder TJ, McCrindle BW, Phillips AB, Blackstone EH, Rajeswaran J, Williams WG, et al. Survival and right ventricular performance for matched children after stage-1 Norwood: modified Blalock-Taussig shunt versus 
right-ventricle-to-pulmonary-artery conduit. J Thorac Cardiovasc Surg. 2015; 150:1440-52. e1-8.

2. Myers JW, Ghanayem NS, Cao Y, Simpson P, Trapp K, Mitchell ME, et al. Outcomes of systemic to pulmonary artery shunts in patients weighing less than $3 \mathrm{~kg}$ : analysis of shunt type, size, and surgical approach. J Thorac Cardiovasc Surg. 2014;147:672-7.

3. Petrucci O, O'Brien SM, Jacobs ML, Jacobs JP, Manning PB, Eghtesady P. Risk factors for mortality and morbidity after the neonatal Blalock-Taussig shunt procedure. Ann Thorac Surg. 2011;92:642-51; discussion 651-2.

4. Dirks V, Prêtre R, Knirsch W, Valsangiacomo Buechel ER, Seifert B, Schweiger M, et al. Modified Blalock Taussig shunt: a not-so-simple palliative procedure. Eur J Cardiothorac Surg. 2013;44:1096-102.

5. Ashburn DA, McCrindle BW, Tchervenkov CI, Jacobs ML, Lofland GK, Bove EL, et al. Outcomes after the Norwood operation in neonates with critical aortic stenosis or aortic valve atresia. J Thorac Cardiovasc Surg. 2003;125: 1070-82.

6. Migliavacca F, Pennati G, Dubini G, Fumero R, Pietrabissa R, Urcelay G, et al. Modeling of the Norwood circulation: effects of shunt size, vascular resistances, and heart rate. Am J Physiol Heart Circ Physiol. 2001;280: H2076-86.

7. Kitaichi T, Chikugo F, Kawahito T, Hori T, Masuda Y, Kitagawa T. Suitable shunt size for regulation of pulmonary blood flow in a canine model of univentricular parallel circulations. J Thorac Cardiovasc Surg. 2003; $125: 71-8$.

8. O'Connor MJ, Ravishankar C, Ballweg JA, Gillespie MJ, Gaynor JW, Tabbutt S, et al. Early systemic-to-pulmonary artery shunt intervention in neonates with congenital heart disease. J Thorac Cardiovasc Surg. 2011;142:106-12.
9. Schmid FX, Kampmann C, Kuroczynski W, Choi YH, Knuf M, Tzanova I, et al. Adjustable tourniquet to manipulate pulmonary blood flow after Norwood operations. Ann Thorac Surg. 1999;68:2306-9.

10. Chikada M, Sekiguchi A, Oho S, Miyamoto T, Ishida R, Takayama H, et al. Dilatable banding of a Blalock-Taussig shunt. Ann Thorac Surg. 2002;74: 253-5.

11. Kuduvalli M, McLaughlin KE, Trivedi DB, Pozzi M. Norwood-type operation with adjustable systemic-pulmonary shunt using hemostatic clip. Ann Thorac Surg. 2001;72:634-5.

12. Pace Napoleone C, Oppido G, Angeli E, Gargiulo G. Adjustable aorto-pulmonary shunt to prevent temporary pulmonary over-circulation. Eur J Cardiothorac Surg. 2006;29:253-4.

13. Honjo O, Benson LN, Mewhort HE, Predescu D, Holtby H, Van Arsdell GS, et al. Clinical outcomes, program evolution, and pulmonary artery growth in single ventricle palliation using hybrid and Norwood palliative strategies. Ann Thorac Surg. 2009;87:1885-92; discussion 1892-3.

14. Kitagawa T, Katoh I, Fukumura Y, Yoshizumi M, Masuda Y, Hori T. Achieving optimal pulmonary blood flow in the first-stage of palliation in early infancy for complex cardiac defects with hypoplastic left ventricles. Cardiol Young. 2008;5: 21-7.

15. Douglas WI, Moore KB, Resig PP, Mohiuddin MW. The adjustable systemicpulmonary artery shunt provides precise control of flow in vivo. ASAIO J. 2010;56:73-6.

Key Words: congenital heart disease, systemic-to-pulmonary shunt 


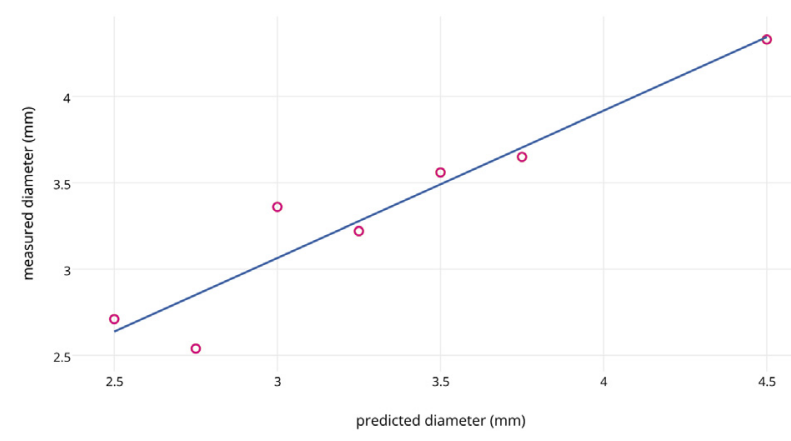

FIGURE E1. Banding accuracy.

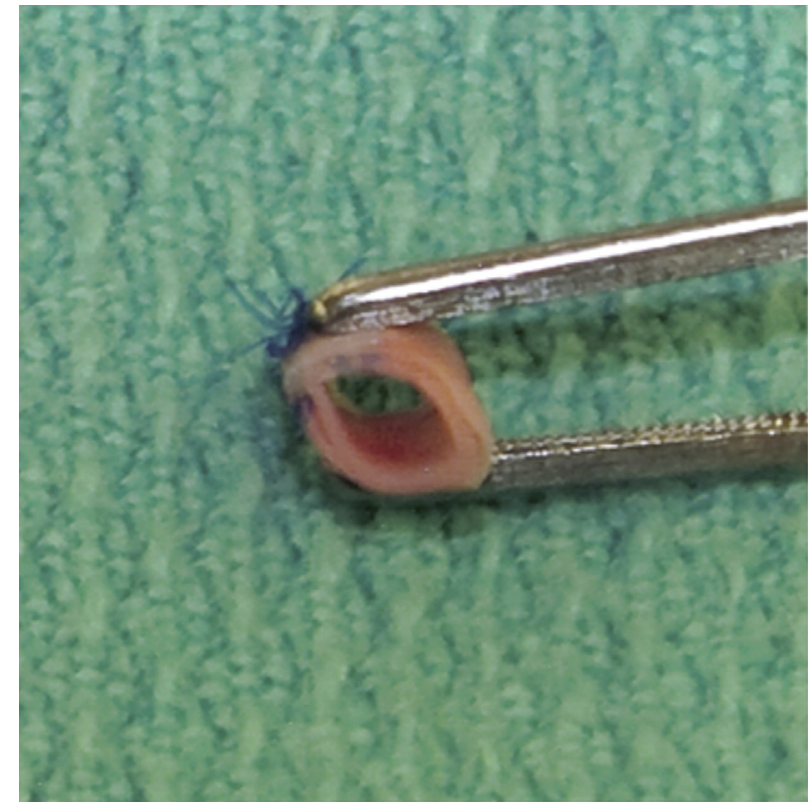

FIGURE E2. Excised banded 3.5-mm Blalock-Taussig shunt at the time of stage II palliation.
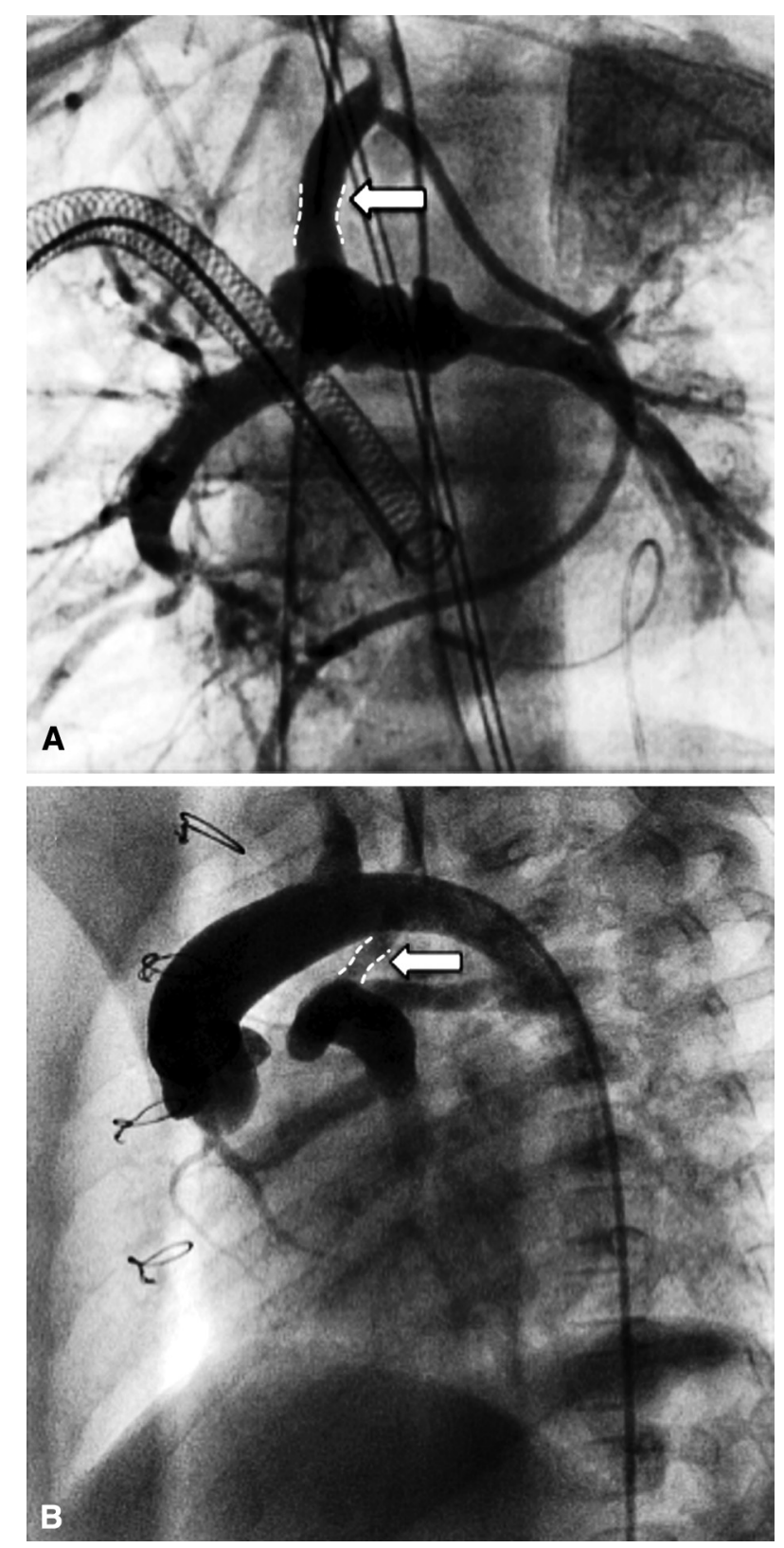

FIGURE E3. Angiograms of banded Blalock-Taussig shunts. Arrows indicate area of shunt banding. (A) Anteroposterior view. (B) Lateral view. 
TABLE E1. Diameters and wall thicknesses of commonly used shunts

\begin{tabular}{lcc}
\hline Manufacturer & Shunt diameter, $\mathbf{~ m m}$ & Wall thickness, $\mathbf{~ m m}$ \\
\hline Impra & 3.0 & 0.58 \\
& 3.5 & 0.58 \\
Gore-Tex & 3.0 & 0.43 \\
& 3.5 & 0.43 \\
& 4.0 & 0.46 \\
5.0 & 0.44 \\
6.0 & 0.43 \\
7.0 & 0.51 \\
& 8.0 & 0.50 \\
& 10.0 & 0.65 \\
\hline
\end{tabular}

TABLE E2. Percent compression for small regular-walled shunts

\begin{tabular}{|c|c|c|c|c|c|c|c|c|}
\hline $\begin{array}{l}\text { Manufacturer } \\
\text { shunt size, } \mathbf{m m}\end{array}$ & $\begin{array}{l}\text { Measured, mm, } \\
\text { mean } \pm \text { SD }\end{array}$ & $\mathbf{n}$ & $\begin{array}{c}\text { Predicted } \\
\text { banding, } \mathbf{m m}\end{array}$ & $\begin{array}{c}\text { Measured banding, mm, } \\
\text { mean } \pm \text { SD }\end{array}$ & $\mathbf{n}$ & $\begin{array}{l}\text { Predicted relative } \\
\text { reduction, } \%\end{array}$ & $\begin{array}{l}\text { Measured relative } \\
\text { reduction, } \%\end{array}$ & Interpretation \\
\hline 3.0 & $3.00 \pm 0.03$ & 15 & 2.50 & $2.95 \pm 0.06$ & 6 & 16.67 & 1.73 & - \\
\hline 3.0 & $2.96 \pm 0.03$ & 7 & 2.75 & $2.92 \pm 0.06$ & 7 & 8.33 & 1.30 & - \\
\hline 3.5 & $3.45 \pm 0.07$ & 8 & 3.00 & $3.32 \pm 0.06$ & 8 & 14.29 & 3.52 & - \\
\hline 3.5 & $3.48 \pm 0.05$ & 7 & 3.25 & $3.45 \pm 0.06$ & 8 & 7.14 & 0.98 & - \\
\hline
\end{tabular}

SD, Standard deviation; +, overbanded; -, underbanded. 